UDC 342.3

LBC 67.011

\title{
UNITY OF THE STATE POWER AS THE BASIC POLITICAL AND LEGAL PRINCIPLE OF STATE CONSTRUCTION: HISTORY AND MODERNITY
}

\author{
Nikolay I. Grachev \\ Volgograd State University, Volgograd, Russian Federation
}

\begin{abstract}
Introduction. The role and functions of the state power in a society suggest its arrangement on the basis of certain principles which are currently not always in line with those set forth by the constitutional legislation as independent foundations of the constitutional order. One of such principles is the principle of state power unity.

Results. This article deals with the political and legal content of this principle, its correlation with the principle of powers separation, historical forms of its effectuation, and modern mechanisms for its implementation in the state construction practice of some particular states. Methods. The research methodology is relied on systemic and structural-functional analysis, concrete historical approach and comparative law approach. Conclusions. Unity of state power is a consistent historical characteristic, being the permanent foundation of state-formed societies which constantly reproduces itself in the course of their evolution, during and after revolutionary transformations, regardless of its confirmation in the constitutional legislation.

Key words: state, state power, supreme power, unity of state power, separation of powers, principle of state power organization, constitutional legislation, state construction.
\end{abstract}

\section{ЕДИНСТВО ГОСУДАРСТВЕННОЙ ВЛАСТИ КАК ОСНОВОПОЛАГАЮЩИЙ ПОЛИТИКО-ПРАВОВОЙ ПРИНЦИП ГОСУДАРСТВЕННОГО СТРОИТЕЛЬСТВА: ИСТОРИЯ И СОВРЕМЕННОСТЬ}

\author{
Николай Иванович Грачев \\ Волгоградский государственный университет, г. Волгоград, Российская Федерация
}

\begin{abstract}
Введение: назначение и функции государственной власти в обществе предполагают ее организацию на основе вполне определенных принципов, которые не всегда совпадают в настоящее время с теми, которые закреплены конституционным законодательством в качестве самостоятельных основ конституционного строя. Одним из таких принципов является принцип единства государственной власти. Результаты: в статье рассматриваются политико-правовое содержание данного принципа, соотношение с принципом разделения властей, исторические формы воплощения, современные механизмы реализации в практике государственного строительства некоторых конкретных государств. Методы: в основе методологии работы находятся методы системного и структурно-функционального анализа, конкретно는 исторический, сравнительно-правовой. Выводы: единство государственной власти есть системно-исто尺) рическая черта, неизменная основа государственно-организованных обществ, постоянно воспроизводящая себя в ходе их эволюции, в процессе и после революционных преобразований, вне зависимости от закрепления в конституционном законодательстве.

Ключевые слова: государство, государственная власть, верховная власть, единство государственной власти, разделение властей, принцип организации государственной власти, конституционное законодательство, государственное строительство.
\end{abstract}




\section{Введение}

С самого момента образования государственности и на протяжении практически всей ее истории, что равнозначно истории человечества, государственная власть выступает как важнейший атрибут (элемент и качественный признак) государства. Она вырастает из потребностей политической организации общества, являясь основной формой управления социальными процессами.

Государственная власть представляет собой выделяемую обществом организованную силу, внешним выражением которой выступает система государственных органов и учреждений, объединяющих все элементы народной жизни в единое политическое целое (государство) путем осуществления общих для всего населения дел, функций организации, управления и поддержания порядка на основе монопольного права на принуждение. Наличие в государстве власти, выполняющей указанные функции, является основной гарантией существования и воспроизводства государствообразующего народа, необходимым условием его благополучия и развития. «Государственная власть есть такое политико-правовое явление, существование которого обусловлено потребностями самостоятельного и независимого существования государства и составляющего его народа среди других государств и народов» [4, с. 44].

Целевое назначение и функции государственной власти предполагают ее организацию и деятельность на основе вполне определенных принципов. Эти принципы, рассматриваемые как идеальное отражение объективно существующих закономерностей общественного развития, доказывали свою реальность и действенность на протяжении всего периода существования государственности. К ним, на наш взгляд, относятся: 1) принцип верховенства государственной власти; 2) публичность государственной власти; 3) единство государственной власти; 4) иерархичность построения системы (организации) государственной власти; 5) легитимность государственной власти.

\section{Принцип единства}

государственной власти

\section{в исторической ретроспективе}

Указанные выше принципы организации и деятельности государственной власти уже давно превратились в ее неотьемлемые качественные характеристики. Они на протяжении всей истории, вне зависимости от их закрепления в конституциях и законодательстве, находили и по-прежнему находят свое выражение и проявление на практике в организации и деятельности государственного аппарата любой страны и одновременно всех их вместе взятых. Гибель конкретных государств и разложение государственности как таковой всегда оказывались связанными с отходом от этих принципов, утратой ими своей реальной действенности. Все они тесно связаны между собой, и умаление или ограничение одного из них отрицательно сказывается на возможности реализации других. Однако системообразующим среди всех указанных выше принципов является, на наш взгляд, принцип единства государственной власти, о чем свидетельствует исторический опыт. Двоевластие в России (февраль октябрь 1917 г., 1990-1991 гг., 1993 г.), борьба короля и парламента в Англии во время английской буржуазной революции $1642-$ 1649 гг., попытка разделения территории Римской империи между несколькими императорами (III-IV вв.) и другие аналогичные события в других странах нивелировали значение и упраздняли позитивный потенциал других принципов, на которых строится государственная власть, приводя их к разрушению или ставя на грань гибели.

В Древнем мире, Средневековье и на пороге Нового времени единство государственной власти понималось прежде всего как организационное единство, которое носило, как правило, персоналистский характер, основываясь на концентрации всей полноты суверенных государственно-властных полномочий законодательного, управительного и судебного характера в руках самодержавного или абсолютного монарха. Идея единства государственной власти оставалась основополагающей для ее организации и деятельности практически до конца XVII - середины XVIII сто- 
летия, когда сначала идеолог «Славной революции» в Англии Дж. Локк (см.: [11, с. 137161]), а затем французский граф-просветитель Ж.Л. Монтескье (см.: [14, с. 138-148]) во Франции выдвинули теорию разделения властей. В научной литературе существует достаточно распространенная точка зрения, что предпосылки теории разделения властей можно обнаружить в трудах античных мыслителей Аристотеля и Полибия, а зачатки ее практического воплощения - в организации верховной власти Римской республики (см., например: [7, с. 11-17, 24]) и ветхозаветного Израиля (см.: [1]). Такая концептуальная позиция выглядит искусственной. Республиканский Рим в действительности стремился к сочетанию в организации своей верховной власти демократических, аристократических и монархических элементов, а не к их разделению. Механизм верховной власти республики, во всяком случае в период ее расцвета, был направлен не на разделение полномочий и взаимный контроль, а на поиск согласия и согласованности в деятельности народных собраний (комиций), сената и консулов, обеспечение их прочного единства (см.: [4, с. 169170]). Это был «принцип дополнения властей», принцип солидарности, где одна не до конца полномочная власть подкрепляла другую такую же [12]. Поэтому Полибий, живший во времена расцвета Римской республики, определил ее форму правления как смешанную, сочетающую лучшие черты трех классических «чистых» форм (см.: [16, с. 12-17]). Что касается ветхозаветного Израиля, то следует отметить, что со времен Иосифа Флавия его форма правления определяется как теократия (см.: [13, с. 261; 19]), при которой Бог властвует над народом посредством пророков и судей (часто и тех, и других в одном лице). И даже в эпоху царств судьи-пророки оставались «концептуальной» закулисной властью. В этом отношении, как мы увидим далее, между современными Великобританией и США и древним Израилем существуют вполне прозрачные аналогии.

Симптоматично, что для Монтескье в качестве идеального образца разделения властей служила организация верховной власти конституционной (дуалистической) монархии в Англии в период после «Славной револю- ции» 1688 года (см.: [14, с. 138]). В последующее время теория разделения властей стала для либерально-демократической государственности и ее концепции незыблемым принципом, не подлежащим критическому обсуждению.

Как показывает история государственного строительства, принцип разделения властей, так же как и все другие либеральнодемократические ценности (приоритет прав личности, верховенство права, частная собственность и рыночное хозяйство, парламентаризм и т. д.) эффективно действуют на своей родной, автохтонной для них почве, в первую очередь в странах англосаксонской политико-правовой культуры. Будучи провозглашенными универсальными, эти принципы на самом деле имеют англосаксонское происхождение и отражают интересы двух сменивших один другого гегемонов мировой капиталистической системы - Великобритании и США, которые, внедряя их последовательно с Запада на Восток в идеологию и практику государственного строительства других стран, устраняли всех своих геополитических конкурентов - сначала полуостровных европейских (Францию и Германию), а затем и евразийских Российскую империю и СССР. Поэтому либеральные принципы организации государства и общества, включая и принцип разделения властей, в Великобритании и США носят созидательный характер, но в отношении стран - их геополитических противников выступают как разрушительное идеологическое и политико-экономическое оружие (см.: [20, с. 6-38]). Происходит это в силу социокультурной близости и адекватности этих принципов породившему их обществу в первом случае и абсолютного их несоответствия социокультурной среде и ментальности населения стран-реципиентов, заимствующих их извне.

Кроме того, необходимо иметь в виду, что принципы демократии, парламентаризма, правового государства (верховенства права), разделения властей не стоит понимать буквально, прямо в соответствии с буквой конституционных положений, тем более что Великобритания до сих пор не имеет писаной конституции. Англосаксонские народы сами вырастили свою государственность, их госу- 
дарственные и правовые институты органичны для их национальной культуры. Поэтому они не сильно озабочены соответствием деятельности своих органов власти теоретическим постулатам или букве конституции. Гораздо важнее общее соответствие институтов власти национальной культуре и менталитету государствообразующего народа и эффективность их деятельности. На практике это приводит к повсеместному верховенству в государственной организации стран Западной Европы и Северной Америки исполнительной власти, ее «главенствующей роли» в отношениях с другими ветвями власти, на что уже давно обратили внимание все внимательные и добросовестные исследователи (см.: [8, с. 100-112]).

Однако самое существенное заключается в том, что в этих странах на протяжении практически всего существования капиталистической формации, а следовательно, и буржуазной государственности официально установленные институты верховной власти не совпадают с ее реальными, фактическими носителями. Реальные субъекты власти создают «теневые» или (и) закрытые (закулисные) структуры, встроенные в конституционный государственный механизм, тесно и неформально с ним связанные, осуществляющие фактическое руководство этим механизмом и стоящие над ним. Именно эти структуры обеспечивают единство государственной, в первую очередь верховной власти в США и Великобритании, пытаясь одновременно осуществлять руководство стратегическим развитием всего мира и опираясь при этом на свое доминирующее влияние в официальных государственных институтах.

В Великобритании это прежде всего уникальный институт монархии, а фактически королевской семьи. Во-первых, исходя из конституционного законодательства монарх обладает огромными полномочиями, которые включают право подписания законов и связанное с этим право абсолютного вето, право роспуска нижней палаты парламента, право назначения премьер-министра, других членов Правительства и судей. Он является верховным главнокомандующим и назначает всех высших должностных лиц в вооруженных силах. Ему принадлежит право заключения меж- дународных договоров, объявления войны и заключения мира. Монарх возглавляет англиканскую церковь в Англии и пресвитерианскую в Шотландии. Кроме того, он возглавляет Содружество (1931-1947 гг. - Британское содружество наций), включающее около 50 государств - бывших колоний и доминионов Великобритании, 17 из которых признают английского короля главой своих государств. Именно институт монархии выступает в Великобритании как символ единства нации и преемственности ее развития, гарант стабильности общества (см.: [9, с. 48-51]). В Великобритании существует официально признанная доктрина верховенства британского парламента, разработанная выдающимися английскими правоведами В. Блэкстоном и А. Дайси, имеющая нормативное значение и являющаяся одним из источников неписаной британской конституции. Согласно ей парламент, под которым формально-юридически понимается король, палата лордов и палата общин, что определяется выражением «король в парламенте», обладает верховной и бесконтрольной властью, «может сделать все, что невозможно физически» [6, с. 47-48]. Если учесть, что в состав палаты общин полностью входит Правительство, поскольку оно формируется из депутатов партии парламентского большинства, а высшей судебной инстанцией является палата лордов, то остается только гадать, как monsieur Монтескье и его многочисленные последователи в прошлом и настоящем смогли углядеть в организации верховной власти Великобритании ее разделение на три организационно независимые друг от друга ветви.

Несмотря на «спящий» характер своих политических прерогатив, монарх и его семья фактически остаются системообразующим элементом в системе верховной власти Соединенного королевства, являясь ключевым финансово-экономическим звеном не только Великобритании, но и всего Содружества, обладающим не только моральным авторитетом, как часто пишется в учебниках по конституционному праву, но и пользующимся определяющим влиянием политического и административного характера, включая блокирование принятия нежелательных судебных решений. 
Как писал по этому поводу еще в начале 30-х гг. прошлого века барон Рауль де Ренне, аксиома, что «английский король царствует, но не управляет», совершенно неверна. «В действительности английский король именно управляет, и правит более самодержавно, чем многие другие монархи, считавшиеся самодержавными и неограниченными. Происходит же это вследствие того, что король является главой особой системы негласных законспирированных установлений, руководящих всеми сторонами государственной и общественной жизни страны». То есть наряду с явными органами власти на всей территории Великобритании «существуют организации, которые скрыто от глаз непосвященных оказывают решающее влияние на внутреннюю и иностранную политику государства». Поэтому «общеизвестная английская форма правления с ее классическим парламентаризмом не соответствует действительному государственному механизму страны», который «состоит из чрезвычайно искусной комбинации явных форм... с тайными, известными только тем, кто принимает в них участие» [17].

Сказанное в полной мере относится и к США. К началу XX в. там окончательно сложилась система, в которой представительные органы (конгресс, его палаты и легислатуры штатов), политические партии, выборы, «жесткое» разделение властей, якобы трансформировавшееся в систему сдержек и противовесов в отношениях между высшими государственными органами, - все это лишь бутафория, рассчитанная на то, чтобы ввести другие народы и своих граждан в заблуждение, направив их действия в нужное русло. За спиной всей этой сложной структуры стоят мощные глобальные олигархические кластеры, которые условно можно обозначить как кланы Рокфеллеров (интересы которых представляет республиканская партия) и Ротшильдов (демократическая партия). Непримиримая борьба между ними, на которой спекулируют некоторые поклонники конспирологии, - миф. На самом деле имеет место имитация борьбы (конкуренция, несомненно, присутствует). Имеющие место противоречия так или иначе всегда разрешаются консенсусом, который достигается путем обсуждения проблем в закрытом режиме на заседаниях неофициальных глобалистских организаций: Совета по международным отношениям, Бильдербергского клуба, Трехсторонней комиссии и др. Достигнутые договоренности безоговорочно выполняются и приводятся в жизнь посредством государственных органов. К тем, кто «выпадает из консенсуса», применяются меры устрашения и воздействия, диапазон которых достаточно широк, от десоциализации и политического забвения до демонстративных убийств, как это случилось с братьями Кеннеди (см.: [15, с. 426-427]). Поэтому какая бы партия не получила большинство в палате представителей или сенате, чей бы представитель не занимал Белый дом, их политика ведется и регулируется одной и той же «концептуальной властью», обладающей реальным верховенством, внутренним единством, несменяемостью и преемственностью, поскольку именно указанные выше бизнес-империи (Ротшильдов и Рокфеллеров) осуществляют функцию реального стратегического руководства развитием США и всего Запада.

Таким образом, конституционно закрепленное разделение властей в государствах теперь уже всей Европы и Северной Америки - все эти парламенты, президенты или правительства, конституционные суды - суть лишь фасад, политико-правовая фикция, опереточная суета не слишком искушенной в политике публики. Реальный суверенитет - верховная власть принятия решений, организации их исполнения и контроля за ним - принадлежит глобальным олигархическим кланам, осуществляющим ее посредством закрытых полуконспиративных структур. Конституционные органы выступают лишь промежуточной ступенью («прокладкой») между «концептуальной» (фактически верховной) властью и подвластными, осуществляя функцию подчиненного управления (по сути административную, исполнительно-распорядительную деятельность), вне зависимости от того, голосуют ли они в парламенте, заседают в правительстве или осуществляют правосудие. Президент или премьер-министр в лучшем случае исполняют роль «смотрящего» в отношении официальных органов, направляя их деятельность в нужном для реальной власти направлении. 


\section{Принцип единства государственной власти в российских конституциях}

В России, наоборот, на протяжении всей ее истории официальная власть всегда совпадала с реальной, вернее, она и была ею. Начиная с конца XV в. и вплоть до революции 1917 г. она существовала в форме самодержавной монархии, которая по существу своему никак не могла быть юридически ограничена или разделена.

После Великого Октября верховная власть в СССР принадлежала высшим партийным органам, представляя собой нечто вроде коллективного, олигархического самодержавия, которое периодически довольно легко превращалось в индивидуальное: партийный лидер (генсек) де-факто превращался в единоличного диктатора, «красного монарха». Однако, несмотря на неконституционный характер (формально высшим органом государственной власти являлся Верховный Совет), партийное самодержавие имело вполне легальный, почти официальный характер с попытками узаконить такое положение конституционно (ст. 126 Конституции СССР 1936 г., ст. 6 Конституции СССР 1977 г.). По крайней мере, КПСС не скрывала своего фактического верховенства, не делала из себя криптократию.

Пришедшие к власти в начале 90-х гг. XX в. либералы попытались сломать 500-летнюю парадигму организации российской власти. В принятой в 1993 г. новой Конституции России за основу были взяты новоевропейские и американские политико-правовые идеи, включая принцип разделения властей, на самом деле являющийся миной под конструкцию любой работающей власти. Парадокс, однако, заключается в том, что за основу новой формы правления в России была взята криптомонархическая модель Пятой республики во Франции, с еще более широкими функциями и полномочиями Президента России, которые подняли его над другими высшими органами, олицетворяющими законодательную, исполнительную и судебную власть, и поставили его вне системы разделения властей. В интерпретации Конституции РФ (см.: [10]) принцип разделения властей весьма напоминает гегелевскую трактовку этой концепции, где все ветви власти объединяются суверенными прерогативами государя, обладающего правом последнего волевого решения (см.: [3, с. 311]), а также план государственных преобразований М.М. Сперанского в эпоху царствования Александра I, который краеугольным камнем своего проекта положил теорию разделения властей, но возвел их все к державной власти государя-императора и объединил в его персоне (см.: [18, c. 399-411]). Весьма значительно также статус Президента России, на наш взгляд, напоминает правовое положение государя-императора по основным законам Российской империи от 23 апреля 1906 г. (см.: [2, с. 311-320]), в соответствии с которыми ее форму правления можно определить как дуалистическую монархию.

Таким образом, несмотря на эклектичность содержания и радикальный либерализм основополагающих принципов, Конституция РФ 1993 г. в организации верховной власти государства по существу воспроизвела российский архетип сильной единоличной власти главы государства, компетенция которого вполне позволяет обеспечивать ключевые принципы, на которых должны строиться эффективно работающий государственный аппарат и вся система государственных учреждений.

Поэтому в настоящее время государственная организация России характеризуется такими чертами, которые не соответствуют букве действующей конституции, но адекватно отвечают духу российской государственности: фактическим подчинением главе государства Федерального Собрания, которое по существу превратилось в законосовещательный орган при Президенте РФ; лишением независимости судебных органов, находящихся под контролем президентской Администрации; практической унитаризацией территориального пространства Российской Федерации; отсутствием реальной почвы для парламентаризма [4, с. 45].

\section{Выводы}

Такое положение не стоит, однако, рассматривать в качестве «узурпации власти Президентом», как это делают лидеры неолиберальной оппозиции. Оно имеет глубинную опору в социокультурной среде и политической системе России, доказывая лишний раз, что единство государственной власти - это системно- 
Н.И. Грачев. Единство государственной власти как основополагающий политико-правовой принцип

историческая черта, неизменяемая и несменяемая основа, всегда воспроизводящая себя в ходе эволюции крупных и сложных социальнополитических систем. В ходе развития такие системы могут менять свои структуры, но, как говорит французская пословица, «чем больше перемен, тем больше все остается по-старому», по крайней мере, по сути, по своим базовым принципам. Более того, структурные кризисы и изменения как раз и обеспечивают лучше всего сохранение системы, постоянно жертвующей своими конкретными историческими формами в целях сохранения фундаментальных, сущностных черт.

\section{СПИСОК ЛИТЕРАТУРЫ}

1. Баренбойм, П. Д. 3000 лет доктрины разделения властей. Суд Съютера / П. Д. Баренбойм. М. : РОССПЭН, 2003. -288 c.

2. Высочайшие утвержденные основные государственные законы 1906 г., 23 апреля // Хрестоматия по истории отечественного государства и права (10 век - 1917 год) / сост. В. А. Томсинов. М. : Зерцало, 2000. - С. 311-320.

3. Гегель, Г. Ф. Философия права / Г. Ф. Гегель. - М. : Мысль, 1990. - 524 с.

4. Грачев, Н. И. Конституция 1993 г. и перспективы развития российского конституционализма / Н. И. Грачев // Вестник Волгоградского государственного университета. Серия 5, Юриспруденция. -2013 . - № 4 (21). - С. 42-48.

5. Грачев, Н. И. Происхождение суверенитета: Верховная власть в мировоззрении и практике государственного строительства традиционного общества / Н. И. Грачев. - М. : Зерцало, 2009. - 320 с.

6. Дайси, А. В. Основы государственного права Англии / А. В. Дайси. - М. : Тип. изд-ва Н.Д. Сытина, 1905.- 681 с.

7. Дмитриев, Ю. А. Система государственной власти в России и в мире: историко-правовая ретроспектива / Ю. А. Дмитриев, А. М. Николаев. М. : Профобразование, 2002. - 840 с.

8. Керимов, А. Д. Современное государство: Вопросы теории / А. Д. Керимов. - М. : Норма, 2008. $-144 \mathrm{c}$.

9. Конституционное (государственное) право зарубежных стран : учебник. В 4 т. Т. 3 / отв. ред. Б. А. Страшун. - М. : БЕК, 1998. - 764 с.

10. Конституция Российской Федерации. - М. : Проспект, 2016. - $32 \mathrm{c}$.

11. Локк, Дж. Два трактата оправлении / Дж. Локк // Соч. В 3 т. Т. 3 / Дж. Локк. - М. : Мысль, 1988. C. $135-405$.
12. Махнач, В. Л. Поиск земного совершенства / В. Л. Махнач // Независимая газета. - 2000. 23 нояб. - Электрон. текстовые дан. - Режим доступа: http://ng.ru/ideas/2000/11/23/ideas.htme. - Загл. с экрана.

13. Мень, А. История религий. В 7 т. Т. 2. Магизм и единобожие / А. Мень. - М. : Слово, 1991. $426 \mathrm{c}$.

14. Монтескье, Ж. Л. О духе законов / Ж. Л. Монтескье. - М. : Мысль, 1999. - 672 с.

15. Павленко, В. Б. Глобальная олигархия. Кланы в мировой политике: история и современность / В. Б. Павленко. - М. : ОТИ, 2015. - 720 с.

16. Полибий. Всеобщая история. В 3 т. Т. 2, кн. 6-25 / Полибий. - СПб. : Наука, 2005. - 422 c.

17. Ренне, Р. де. Тайный смысл нынешних и грядущих событий / Р. де Ренне. - Электрон. текстовые дан. - Режим доступа: http://www.sites.googele.com/ site. - Загл. с экрана.

18. Сперанский, М. М. Руководство к познанию законов / М. М. Сперанский. - СПб. : Наука, 2002. $680 \mathrm{c}$.

19. Флавий, И. О древностях иудейского народа (Против Апиона) / И. Флавий. - Электрон. текстовые дан. - Режим доступа: $h$ ttp://www.profilil.com/ kniga/22671/iosif. - Загл. с экрана.

20. Фурсов, А. И. Европейская система государств, англосаксы и Россия / А. И. Фурсов // Мировая борьба. Англосаксы против планеты / А. И. Фурсов. - М. : Книжный мир, 2016. $512 \mathrm{c}$.

21. Фурсов, А. И. Русская власть, Россия и Евразия: Великая монгольская держава, самодержавие и коммунизм в больших циклах истории (trestres grund espace dans une tres-tres longue duree) / А. И. Фурсов // Русский интерес / А. И. Фурсов. М. : Товарищество научных изданий КМК, 2014. C. $98-171$.

\section{REFERENCES}

1. Barenboym P.D. 3000 let doktriny razdeleniya vlastey. Sud Syutera [3000 Years of the Doctrine of Powers Separation. Court Syutera]. Moscow, ROSSPEN Publ., 2003. 288 p.

2. Vysochayshie utverzhdennye osnovnye gosudarstvennye zakony 1906 g., 23 aprelya [The Highest Approved Basic Laws of the State in 1906, April 23]. Tomsinov V.A. Khrestomatiya po istorii otechestvennogo gosudarstva i prava (10 vek1917 god) [Anthology on the History of Russian State and Law (10th century - 1917)]. Moscow, Zertsalo Publ., 2000, pp. 311-320.

3. Gegel G.F. Filosofiya prava [Philosophy of Law]. Moscow, Mysl Publ., 1990. 524 p. 
4. Grachev N.I. Konstitutsiya 1993 g. i perspektivy razvitiya rossiyskogo konstitutsionalizma [Constitution of 1993 and Prospects of Russian Constitutionalism Development]. Vestnik Volgogradskogo gosudarstvennogo universiteta. Seriya 5, Yurisprudentsiya [Science Journal of Volgograd State University. Jurisprudence], 2013, no. 4 (21), pp. 42-48.

5. Grachev N.I. Proiskhozhdenie suvereniteta: Verkhovnaya vlast $v$ mirovozzrenii $i$ praktike gosudarstvennogo stroitelstva traditsionnogo obshchestva [Sovereignty Origin: The Supreme Power in the Outlook and Practice of State Building of the Traditional Society]. Moscow, Zertsalo Publ., 2009.320 p.

6. Daysi A.V. Osnovy gosudarstvennogo prava Anglii [Foundations of Public Law of England]. Moscow, Tip. izd-va N.D. Sytina, 1905. 681 p.

7. Dmitriev Yu.A., Nikolaev A.M. Sistema gosudarstvennoy vlasti $v$ Rossii $i v$ mire: istorikopravovaya retrospektiva [The System of State Power in Russia and in the World: Historical and Legal Retrospective]. Moscow, Profobrazovanie Publ., 2002. $840 \mathrm{p}$.

8. Kerimov A.D. Sovremennoe gosudarstvo: Voprosy teorii [Modern State: Theoretical Issues]. Moscow, Norma Publ., 2008. 144 p.

9. Strashun B.A., ed. Konstitutsionnoe (gosudarstvennoe) pravo zarubezhnykh stran: uchebnik. V 4 t. T. 3 [Constitutional (State) Law of Foreign Countries: Textbook. In 4 vols. Vol. 3]. Moscow, BEK Publ., 1998. $764 \mathrm{p}$.

10. Konstitutsiya Rossiyskoy Federatsii [The Constitution of the Russian Federation]. Moscow, Prospekt Publ., 2016. 32 p.

11. Locke J. Dva traktata o pravlenii. Soch. $V 3 t$. T. 3 [Two Treatises on Government. Works in 3 vols. Vol. 3]. Moscow, Mysl Publ., 1988, pp. 135-405.

12. Makhnach V. L. Poisk zemnogo sovershenstva [Search for Earthly Perfection].
Nezavisimaya gazeta, 2000, November 23. Available at: http://ng.ru/ideas/2000/11/23/ideas.htme.

13. Men A. Istoriya religiy: $V 7$ t. T.2 Magizm $i$ Edinobozhie [History of Religions: in 7 vols. Vol. 2 Magic and Monotheism]. Moscow, Saint Petersburg, Slovo Publ., 1991. $426 \mathrm{p}$.

14. Monteskye Zh.L. O dukhe zakonov [On the Spirit of Laws]. Moscow, Mysl Publ., 1999. 672 p.

15. Pavlenko V.B. Globalnaya oligarkhiya. Klany v mirovoy politike: istoriya $i$ sovremennost [Global Oligarchy. Clans in World Politics: History and Modernity]. Moscow, OTI Publ., 2015. 720 p.

16. Polibiy. Vseobshchaya istoriya. V $40 \mathrm{kn} . T 2$. Kn. 6-25 [General History. In 40 books. Vol. 2. Books 625]. Saint Petersburg, Nauka Publ., 2005. 422 p.

17. Renne R. de. Taynyy smysl nyneshnikh $i$ gryadushchikh sobytiy [Secret Meaning of the Present and Future Events]. Available at: sites.googele.com/site.

18. Speranskiy M.M. Rukovodstvo k poznaniyu zakonov [Guide to the Knowledge of Laws]. Saint Petersburg, Nauka Publ., 2002. 680 p.

19. Flaviy I. $O$ drevnostyakh iudeyskogo naroda (Protiv Apiona) [On Antiquities of the Jewish People (Contra Apion)]. Available at: profilil.com/kniga/22671/iosif.

20. Fursov A.I. Evropeyskaya sistema gosudarstv, anglosaksy i Rossiya. Mirovaya borba. Anglosaksy protiv planet [The European System of States, Anglo-Saxons and Russia. The Global Struggle. The Anglo-Saxons against the Planet]. Moscow, Knizhnyy mir Publ., 2016.512 p.

21. Fursov A.I. Russkaya vlast, Rossiya i Evraziya: Velikaya mongolskaya derzhava, samoderzhavie i kommunizm v bolshikh tsiklakh istorii (tres-tres grund espace dans une tres-tres longue duree) [Russian Power, Russia and Eurasia: Great Mongolian State, Autocracy and Communism in the Great Cycle of History (tres-tres grund espace dans une tres-tres longue duree)]. Russkiy interes [Russian Interest]. Moscow, Tovarishchestvo nauchnykh izdaniy KMK, 2014. pp. 98-171.

\section{Information About the Author}

Nikolay I. Grachev, Doctor of Juridical Sciences, Professor, Department of Civil and International Private Law, Volgograd State University, Base Department of Southern Scientific Center of the Russian Academy of Sciences, Prosp. Universitetsky, 100, 400062 Volgograd, Russian Federation, grachev.n.i@mail.ru, gimchp@volsu.ru.

\section{Информация об авторе}

Николай Иванович Грачев, доктор юридических наук, профессор кафедры гражданского и международного частного права, Волгоградский государственный университет, базовая кафедра ЮНЦ РАН, просп. Университетский, 100, 400062 г. Волгоград, Российская Федерация, grachev.n.i@mail.ru, gimchp@volsu.ru. 